\title{
Neuroprotective effects of vitexin against isoflurane-induced neurotoxicity by targeting the TRPV1 and NR2B signaling pathways
}

\author{
LINLIN CHEN, BIN ZHANG, SHIQIANG SHAN and XIN ZHAO \\ Department of Anesthesiology, The Cangzhou Central Hospital, Cangzhou, Hebei 061000, P.R. China
}

Received August 11, 2015; Accepted July 12, 2016

DOI: $10.3892 / \mathrm{mmr} .2016 .5948$

\begin{abstract}
Vitexin is a bioactive compound extracted from hawthorn leaves, which reduces blood pressure and has anti-inflammatory and potential anticancer effects. However, the mechanisms underlying the protective effects of vitexin against isoflurane-induced neurotoxicity remain elusive. Therefore, the aim of the present study was to investigate these mechanisms further. Sprague Dawley rats received $1.4 \%$ isoflurane in a $100 \%$ oxygen environment for $2 \mathrm{~h}$. Human PC12 pheochromocytoma neurosecretory cells were exposed to $2 \%$ isoflurane for $12 \mathrm{~h}$ before they were treated with 1,10 or $100 \mu \mathrm{M}$ vitexin for a further $24 \mathrm{~h}$. Vitexin inhibited the isoflurane-induced cell cytotoxicity and weakened isoflurane-induced neuroinflammation and oxidative stress pathways in PC12 cells. In addition, treatment with vitexin suppressed isoflurane-induced caspase- 3 activation and increased $\beta$-secretase 1 levels in PC12 cells. Furthermore, vitexin treatment decreased the levels of isoflurane-induced cytosolic calcium and reactive oxygen species, and downregulated the expression of transient receptor potential cation channel subfamily V member 1 (TRPV1) and glutamate ionotropic receptor NMDA type subunit $2 \mathrm{~B}$ (NR2B) protein expression in isoflurane-treated PC12 cells. These results suggest that vitexin mediates its protective effects against isoflurane-induced neurotoxicity by targeting the TRPV1 and NR2B signaling pathways.
\end{abstract}

\section{Introduction}

Since the discovery of inhalation anesthetics and their clinical application, researchers have gained an improved understanding of 'inhalation anesthetics and inhalation anesthesia' (1). The

Correspondence to: Dr Bin Zhang, Department of Anesthesiology, The Cangzhou Central Hospital, 16 Xinhua Road, Cangzhou, Hebei 061000, P.R. China

E-mail: zhangbbbcz@163.com

Key words: vitexin, isoflurane, neurotoxicity, transient receptor potential cation channel subfamily $\mathrm{V}$ member 1, glutamate ionotropic receptor N-methyl-D-aspartate type subunit 2B advantages and disadvantages of inhalation anesthetics are continuously being elucidated, and inhalation anesthetics with obvious deficiencies subsequently fall into disuse (2). Recently, inhalation anesthesia has become the primary method for general anesthesia (3). Inhalation anesthetics are metabolized and decompose in organisms (4). The majority of inhalation anesthetics can discharge through the lungs in their primary forms. Therefore, they are safe and effective, and have a higher controllability (5). However, researchers are continuously trying to identify safer inhalation anesthetics (6). Isoflurane is a type of halocarbon inhalation anesthetic first identified in the 1970s, which has a high efficiency and controllability, and serves an important role in maintaining the effects of general anesthesia $(7,8)$.

Recent studies investigating the mechanisms of neuron damage and protection in the central nervous system have made significant progress $(8,9)$. These studies have provided information about how calcium channels, the cell membrane potential and various transmitters influence neuron damage and protection (10). Thus, the principles of general inhalation anesthesia may be further elucidated, including the clinical anesthesia phenomenon, and an increased understanding of the unwanted effects of these may help to avoid their side effects.

The state of consciousness is dependent on the electrophysiological characteristics of the central nervous system (11). The mechanisms of general anesthesia by isoflurane involve the hyperpolarization of nerve cells (12). However, a previous study demonstrated that isoflurane can induce virulence in different nerve cells (12). By contrast, the pre-processing of isoflurane by nerve cells has also been shown to exhibit neuroprotective effects, however, the mechanisms involved in this process are currently unclear (13). $\mathrm{Ca}^{2+}$ serves an essential role as a signaling molecule in nerve cells. An imbalance can result in excess $\mathrm{Ca}^{2+}$, which may be caused by neurocyte injury (14).

The transient receptor potential cation channel subfamily $\mathrm{V}$ member 1 (TRPV1) receptor is universally expressed across the central nervous system, including the hippocampus, cerebral cortex and thalamus (15). During isoflurane-induced neurotoxicity, cellular edema resulting from disrupted energy metabolism may activate the TRPV1 receptor by altering the tension of the cytomembrane (16). In addition, lipid dysbolism of the cytomembrane occurs when the brain is ischemic, which increases the levels of free arachidonic acid (17). Oxygen and glucose deprivation, due to pharmacon-mediated TRPV1 
receptor inhibition, leads to neuronal loss in region 1 of the hippocampus proper due to cellular edema, which has protective functions (18).

Glutamate excitotoxity is considered to be the primary mechanism underlying neuron injury induced by cerebral ischemia (19). When isoflurane-induced neurotoxicity occurs, a large quantity of excitatory neurotransmitters are released from presynaptic membranes due to disruption of metabolic cellular energy and the depolarization of cytomembranes (20). This leads to the elimination of glutamic acid, which accumulates between synaptic clefts. Glutamic acid binds to and activates postsynaptic membranes, resulting in the opening of $\mathrm{N}$-methyl-D-aspartate (NMDA) ion channels, and an excess influx of $\mathrm{Ca}^{2+}(21)$.

The rosaceous hawthorn plant is used as a digestion aid in traditional Chinese medicine (22). Modern pharmacological methods have discovered that flavonoid compounds extracted from Chinese hawthorn leaves can regulate the lipid profile of blood, reduce blood pressure, enhance the outflow volume of the extracorporeal coronary artery, resist oxidation and protect the ischemic myocardium (23). Vitexin is an active compound extracted from hawthorn leaves, which has protective functions during myocardial ischemia (24). A previous study demonstrated that Chinese hawthorn leaves may possess cardiotonic, antianginal, antiarrhythmic and antioxidative properties, and mitigate the effects of acute myocardial ischemia (25). Therefore, the aim of the present study was to investigate whether vitexin may also protect against isoflurane-induced neurotoxicity.

\section{Materials and methods}

Rat details. A total of 30 male Sprague Dawley rats (250-300 g) were obtained from the Experimental Animal Center of the Central Hospital of Cangzhou (Hebei, China). The rats were maintained in $12 \mathrm{~h}$ dark/light cycles at $23 \pm 2^{\circ} \mathrm{C}$ with $55 \pm 5 \%$ humidity, and provided with food and water ad libitum. The animal procedures used in this study were approved by the Standing Committee on Animals at The Central Hospital of Cangzhou.

Isoflurane and vitexin treatment of rats and visualization of neuron cells. A total of 30 Sprague Dawley rats were separated at random into the following five equally-sized treatment groups: i) Control; ii) isoflurane-treated; and iii) $1 \mathrm{mg} / \mathrm{kg}$; iv) $3 \mathrm{mg} / \mathrm{kg}$; and v) $10 \mathrm{mg} / \mathrm{kg}$ vitexin-treated groups, respectively. The isoflurane and vitexin-treated groups were exposed to $1.4 \%$ isoflurane (Sigma-Aldrich; Merck Millipore, Darmstadt, Germany) in a 100\% oxygen environment for $2 \mathrm{~h}$. Following isoflurane treatment, the vitexin-treated group additionally received 1,3 and $10 \mathrm{mg} / \mathrm{kg}$ vitexin (Sigma-Aldrich; Merck Millipore) for $30 \mathrm{~min}$. The rats were euthanized using decollation under anesthesia. Samples of rat brain tissue slices were fixed in $10 \%$ formalin buffer overnight and then dehydrated using $90 \%$ ethanol for $1 \mathrm{~h}$ and $100 \%$ ethanol for $2 \mathrm{~h}$. They were subsequently cleared with xylene for $2 \mathrm{~h}$ and then embedded in paraffin at $60^{\circ} \mathrm{C}$.

Cell lines. Human PC12 pheochromocytoma neurosecretory cells were cultured in high-glucose Dulbecco's modified
Eagle's medium (Hyclone; GE Healthcare Life Sciences, Logan, UT, USA) containing $9 \%$ heat-inactivated fetal calf serum (Invitrogen; Thermo Fisher Scientific, Inc., Carlsbad, CA, USA), $100 \mathrm{U} / \mathrm{ml}$ penicillin, $100 \mu \mathrm{g} / \mathrm{ml}$ streptomycin, and 2 mM L-glutamine (Thermo Fisher Scientific, Inc.), and were maintained in an incubator at $37^{\circ} \mathrm{C}$ in $5 \% \mathrm{CO}_{2}$ and with $95 \%$ humidity.

Cell treatment and viability analysis. PC12 cells were seeded at a density of $1 \times 10^{4}$ cells/well in 96 -well plates before they were exposed to $2 \%$ isoflurane for $12 \mathrm{~h}$ and then cultured with 1,10 and $100 \mu \mathrm{M}$ vitexin for $24 \mathrm{~h}$. MTT solution (Beyotime Institute of Biotechnology, Haimen, China) was added into each well at a final concentration of $0.5 \mathrm{mg} / \mathrm{ml}$ and cells were subsequently incubated at $37^{\circ} \mathrm{C}$ for $4 \mathrm{~h}$. Dimethyl sulfoxide solution (98\%; $150 \mu$ l; Sangon Biotech Co., Ltd., Shanghai, China) was then added to each well. The optical density (OD) was read at $570 \mathrm{~nm}$ using the Universal Microplate Reader (Elx800; BioTek instruments, Inc., Winooki, VT, USA).

Enzyme-linked immunosorbent assay (ELISA). PC12 cells were seeded at a density of $1 \times 10^{4}$ cells/well in 96-well plates before they were exposed to $2 \%$ isoflurane for $12 \mathrm{~h}$ and then treated with 1,10 and $100 \mu \mathrm{M}$ vitexin for $24 \mathrm{~h}$. PC12 cells were immediately collected and centrifuged at 4,000 x $g$ for $10 \mathrm{~min}$. ELISA kits (Nanjing Jiancheng Bioengineering Institute, Nanjing, China) were used to measure serum tumor necrosis factor- $\alpha$ (TNF- $\alpha$; cat. no. R019), interleukin-6 (IL-6; cat. no. R016), glutathione synthetase (GSH; cat. no. A005) and superoxide dismutase (SOD; cat. no. A001-1) concentrations.

Western blot analysis. PC12 cells were seeded at a density of $2 \times 10^{6}$ cells/well in 6-well plates before they were exposed to $2 \%$ isoflurane for $12 \mathrm{~h}$ and then treated with 1,10 and $100 \mu \mathrm{M}$ vitexin for $24 \mathrm{~h}$. PC12 cells were subsequently harvested in RIPA Lysis Buffer with protease inhibitors (Santa Cruz Biotechnology, Inc., Dallas, TX, USA) and total protein was extracted by centrifuging at $12,000 \times \mathrm{g}$ for $10 \mathrm{~min}$ at $4^{\circ} \mathrm{C}$, and according to the manufacturer's instructions. Protein samples $(50 \mu \mathrm{g})$ were separated using $12 \%$ sodium dodecyl sulfate-polyacrylamide gel electrophoresis and then transferred to polyvinylidene fluoride membranes (EMD Millipore, Billerica, MA, USA). Membranes were blocked with 5\% non-fat milk diluted in tris-phosphate buffer containing $0.05 \%$ Tween 20 for $1 \mathrm{~h}$, and incubated overnight at $4^{\circ} \mathrm{C}$ with the following primary antibodies: Polyclonal caspase-3 (cat. no. sc-56052; dilution, 1:1,000; Santa Cruz Biotechnology, Inc.); $\beta$-secretase 1 (BACE; cat. no. sc-365948; dilution, 1:1,000; Santa Cruz Biotechnology, Inc.); transient receptor potential cation channel subfamily V member 1 (TRPV1; cat. no. PAB27817; dilution, 1:1,000; Santa Cruz Biotechnology, Inc.); glutamate ionotropic receptor NMDA type subunit 2B (NR2B; cat. no. 14544; dilution, 1:1,000; Cell Signaling Technology, Inc., Danvers, MA, USA); and GAPDH (cat. no. sc-365062; dilution, 1:10,000; Santa Cruz Biotechnology, Inc.). The membranes were incubated with the anti-mouse or anti-rabbit IgG-horseradish peroxidase-conjugated secondary antibody, (cat. nos. SN133 and SN134, respectively; dilution, 1:5,000; Sunshine Biotechnology Co., Ltd., Nanjing, China), 
and bands were visualized using an enhanced chemiluminescence method.

Reactive oxygen species (ROS) measurement. PC12 cells were seeded at a density of $1 \times 10^{4}$ cells/well in 96-well plates before they were exposed to $2 \%$ isoflurane for $12 \mathrm{~h}$ and treated with 1 , 10 and $100 \mu \mathrm{M}$ vitexin for $24 \mathrm{~h}$. PC12 cells were cultured with 2',7'-dichlorofluorescein diacetate for $6 \mathrm{~h}$, then incubated with cell lysis buffer (OxiSelect ROS assay kit; Cell Biolabs, Inc., San Diego, CA, USA) for $5 \mathrm{~min}$ at room temperature. The OD was read at $480 / 530 \mathrm{~nm}$ using the aforementioned microplate reader (Bio-Tek instruments, Inc.).

Analysis of cytosolic calcium levels. The levels of cytosolic calcium were determined as described previously (26). PC12 cells were treated with isoflurane and vitexin using the aforementioned procedures, before they were treated with Fura-2 (Invitrogen; Thermo Fisher Scientific, Inc.) and perfused with Tyrode's buffer. The levels of cytosolic calcium were recorded using a spectrofluoroscopy system (IonOptix, Westwood, MA, USA) at 340/380 nm.

Statistical analysis. Data are expressed as the mean \pm standard deviation. Experiments for each treatment group was conducted in triplicate. Statistical analyses were performed using the Student's $t$-test and $\mathrm{P}<0.05$ was considered to indicate a statistically significant difference.

\section{Results}

Vitexin protects against isoflurane-induced neurotoxicity in rat brain tissue slices. The chemical structure of vitexin is shown in Fig. 1. Since isoflurane treatment of rats results in neurotoxicity, the initial aim of this study was to examine the potential neuroprotective effects of vitexin in isoflurane-treated rats. The number of neuron cells in the control group was markedly higher than that of the isoflurane-induced group (Fig. 2A and B). A notable increase in neuron cells was observed in the isoflurane plus vitexin $(10 \mathrm{mg} / \mathrm{kg})$-treated group compared with the isoflurane-treated group (Fig. 2B and E).

Vitexin increases the growth of isoflurane-treated PC12 cells. To determine whether the neuroprotective effects of vitexin following isoflurane treatment involves cell growth, the growth of human PC12 pheochromocytoma neurosecretory cells following treatment with isoflurane and vitexin was investigated. As shown in Fig. 3, a significant increase in the growth of PC12 cells was observed following isoflurane plus 10 or $100 \mu \mathrm{M}$ vitexin treatment, compared with isoflurane treatment alone $(\mathrm{P}=0.0079$ and 0.0021 , respectively).

Vitexin prevents the activation of isoflurane-induced inflammatory signaling pathways. Considering the key role of induced neuroinflammation in aged rodents (27), the neuroprotective effects of vitexin in inhibiting the level of pro-inflammatory cytokines, TNF- $\alpha$ and IL-6, in isoflurane-treated PC12 cells was investigated using ELISA. As shown in Fig. 4, treatment of PC12 cells with isoflurane plus 10 or $100 \mu \mathrm{M}$ vitexin, significantly reduced TNF- $\alpha(\mathrm{P}=0.0088$ and 0.0038 , respectively) and IL-6 $(\mathrm{P}=0.0066$ and 0.0049 , respectively) protein levels compared with isoflurane treatment alone.

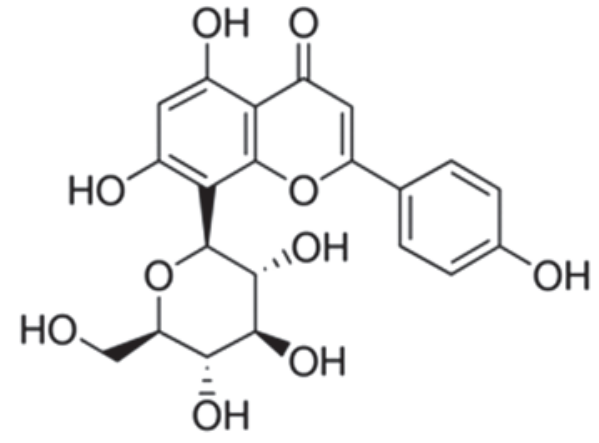

Figure 1. The chemical structure of vitexin.
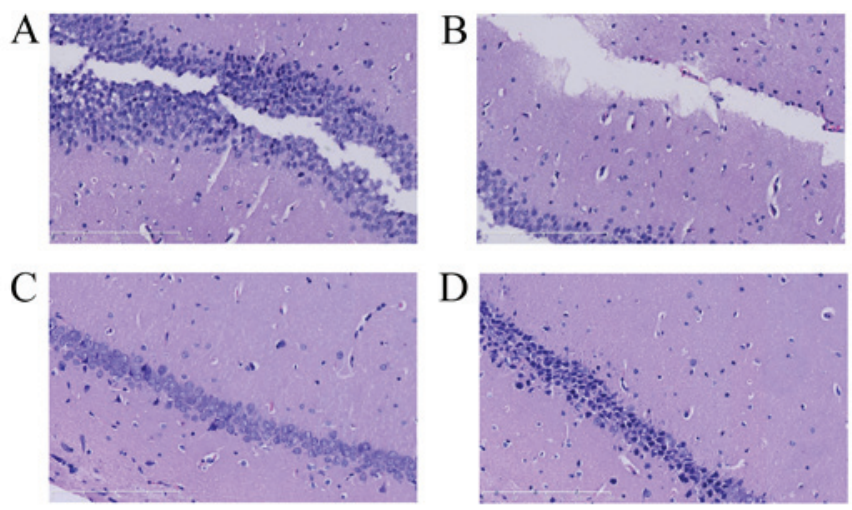

$\mathrm{E}$

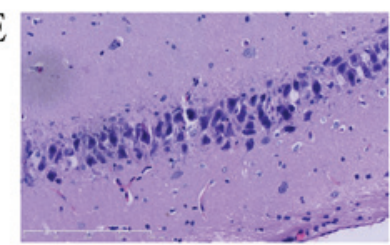

Figure 2. Vitexin protects against isoflurane-induced neurotoxicity in rat brain tissue slices. Tissue slices of (A) Control (B) isoflurane-treated, and isoflurane plus (C) $1 \mathrm{mg} / \mathrm{kg}$ (D) $3 \mathrm{mg} / \mathrm{kg}$ and (E) $10 \mathrm{mg} / \mathrm{kg}$ vitexin-treated groups (magnification, x200).

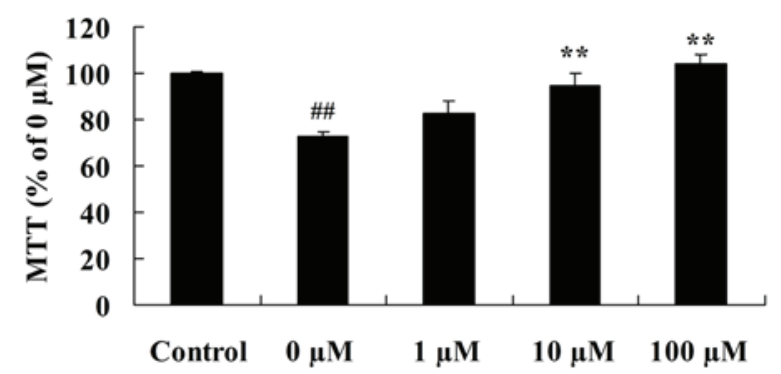

Figure 3. Vitexin increases the growth of isoflurane-treated PC12 cells. MTT assay of PC12 cells treated without (control) or with $2 \%$ isoflurane plus 0,1 , 10 and $100 \mu \mathrm{M}$ vitexin. ${ }^{\# \#} \mathrm{P}<0.01$ vs. control group; ${ }^{* *} \mathrm{P}<0.01$ vs. the $0 \mu \mathrm{M}$ vitexin-treated group.

Vitexin protects against the isoflurane-induced increase in oxidative stress. Considering the key role of oxidative stress in isoflurane-induced PC12 cells, the neuroprotective effects of vitexin against isoflurane-induced GSH and SOD protein expression levels were investigated. As shown in Fig. 5A and B, isoflurane-induced GSH and SOD concentrations in PC12 cells 

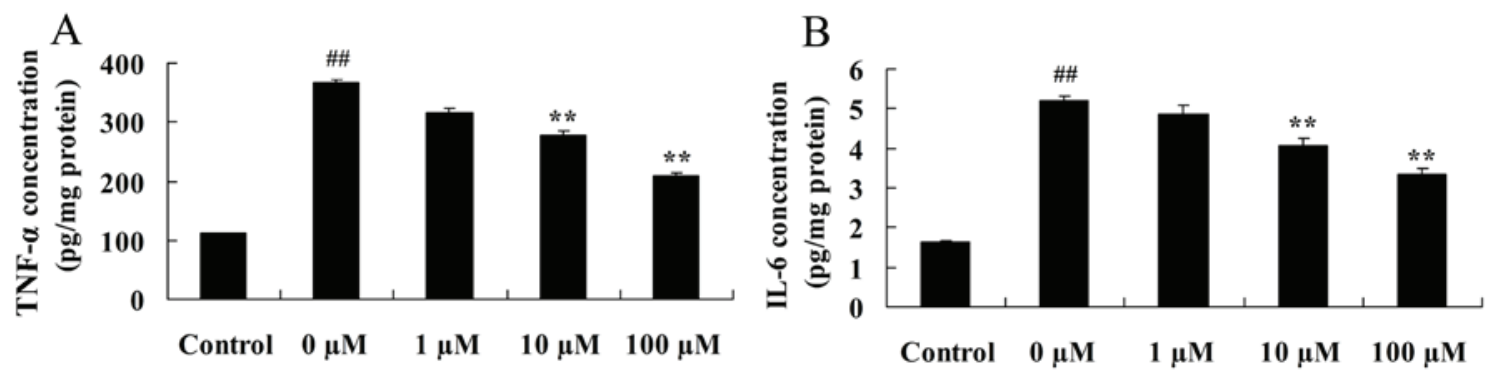

Figure 4. Vitexin protects against isoflurane-induced activation of pro-inflammatory cytokines. The protein concentrations of (A) TNF- $\alpha$ and (B) IL-6 in PC12 cells treated without (control) or with $2 \%$ isoflurane plus $0,1,10$ and $100 \mu \mathrm{M}$ vitexin as determined by ELISA. ${ }^{\# \#} \mathrm{P}<0.01$ vs. control group; ${ }^{* *} \mathrm{P}<0.01 \mathrm{vs}$. the $0 \mu \mathrm{M}$ vitexin-treated group. TNF- $\alpha$, tumor necrosis factor- $\alpha$; IL-6, interleukin-6.
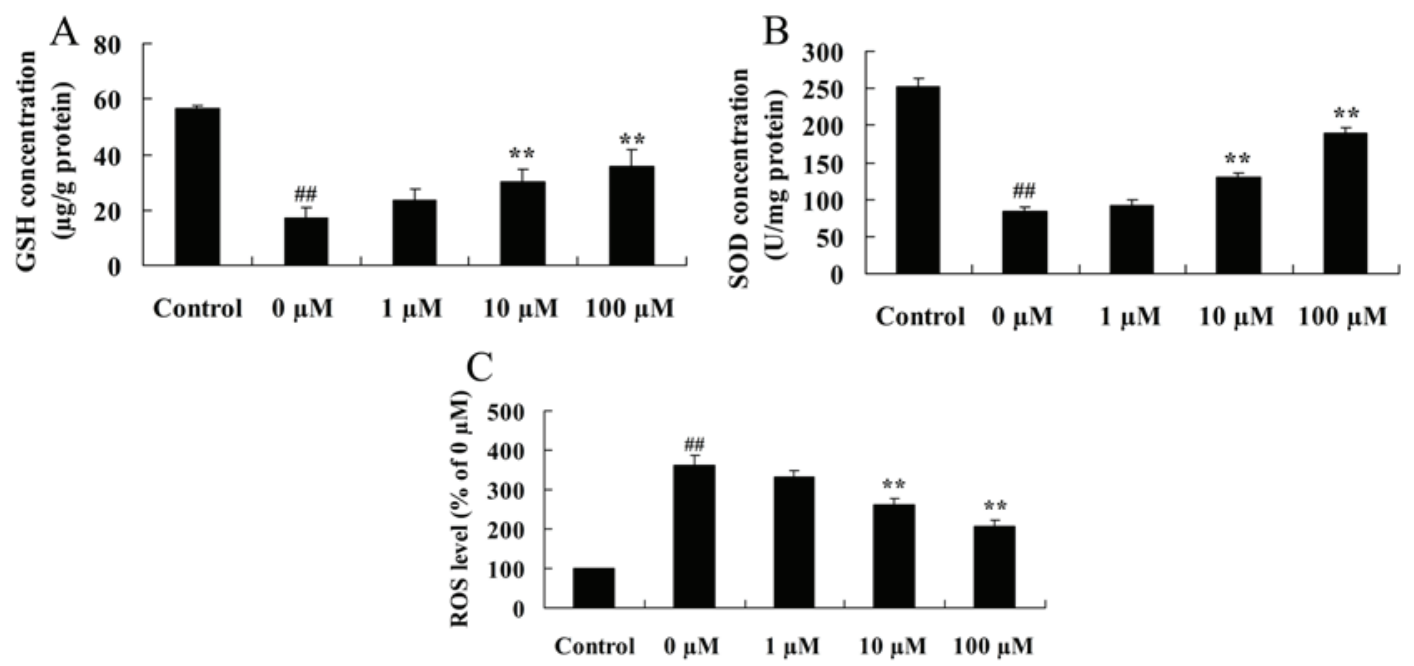

Figure 5. Vitexin protects against isoflurane-induced oxidative stress. The protein concentrations of (A) GSH and (B) SOD as determined by ELISA, and the (C) cellular ROS levels in PC12 cells treated without (control) or with $2 \%$ isoflurane plus $0,1,10$ and $100 \mu \mathrm{M}$ vitexin-treated PC12 cells. ${ }^{\# \#} \mathrm{P}<0.01$ vs. control group; ${ }^{* *} \mathrm{P}<0.01$ vs. the $0 \mu \mathrm{M}$ vitexin-treated group. GSH, glutathione synthetase; SOD, superoxide dismutase; ROS, reactive oxygen species.

were significantly increased following pretreatment of cells with 10 or $100 \mu \mathrm{M}$ vitexin (GSH, $\mathrm{P}=0.0069$ and 0.0033 ; SOD, $\mathrm{P}=0.0059$ and 0.0025 for 10 and $100 \mu \mathrm{M}$ vitexin, respectively). In addition, as shown in Fig. 5C, PC12 cells treated with isoflurane plus 10 and $100 \mu \mathrm{M}$ vitexin, demonstrated a significant reduction in ROS levels compared with isoflurane-treated PC12 cells $(\mathrm{P}=0.0041$ and 0.0018 , respectively).

Vitexin protects against isoflurane-induced caspase-3 activation. In order to investigate the neuroprotective effects of vitexin against isoflurane-induced caspase- 3 activation, the protein expression levels of caspase-3 in isoflurane and vitexin-treated PC12 cells were determined using western blot analysis. Caspase-3 protein expression levels in isoflurane-treated $\mathrm{PC} 12$ cells were significantly reduced following treatment with 10 and $100 \mu \mathrm{M}$ vitexin $(\mathrm{P}=0.0069$ and 0.0033 , respectively; Fig. 6).

Vitexin protects against the isoflurane-induced increase in $B A C E$ protein expression. A previous study demonstrated that BACE promotes amyloid beta peptide production and affects the inhibition of hypomnesis (28). Therefore, the neuroprotective effect of vitexin against isoflurane-induced BACE levels was investigated by evaluating BACE protein expression levels in isoflurane plus vitexin-treated PC12cellsusing western blot analysis. As demonstrated in Fig. 7, treatment of PC12 cells with 10 or $100 \mu \mathrm{M}$ vitexin following exposure to isoflurane, was associated with a significant reduction in BACE protein expression levels $(\mathrm{P}=0.0042$ and 0.0018 , respectively).

Vitexin protects against the isoflurane-induced increase in cytosolic calcium levels. To investigate the role of vitexin in preventing the isoflurane-induced increase in cytosolic calcium levels, the levels of cytosolic calcium in isoflurane-induced PC12 cells following vitexin treatment were investigated. As demonstrated in Fig. 8, cytosolic calcium levels in isoflurane-induced PC12 cells were significantly reduced following treatment with 10 and $100 \mu \mathrm{M}$ vitexin $(\mathrm{P}=0.0031$ and 0.0009 , respectively).

Vitexin protects against the isoflurane-induced increase in TRPV1 expression levels. In order to further investigate the neuroprotective role of vitexin in isoflurane-treated PC12 cells, TRPV1 protein expression levels were examined in isoflurane-treated PC12 cells following treatment with vitexin using western blot analysis. As shown in Fig. 9, treatment with 10 and $100 \mu \mathrm{M}$ vitexin significantly suppressedTRPV1 protein expression in isoflurane-treated PC12cells $(\mathrm{P}=0.0023$ and 0.0005 , respectively). 
A

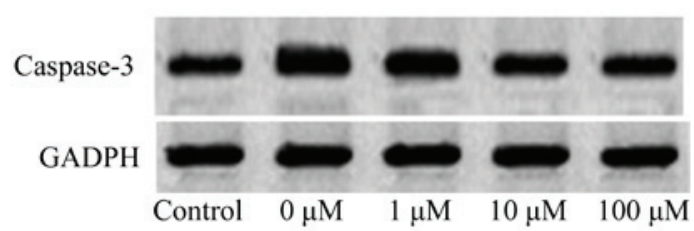

$\mathrm{B}$

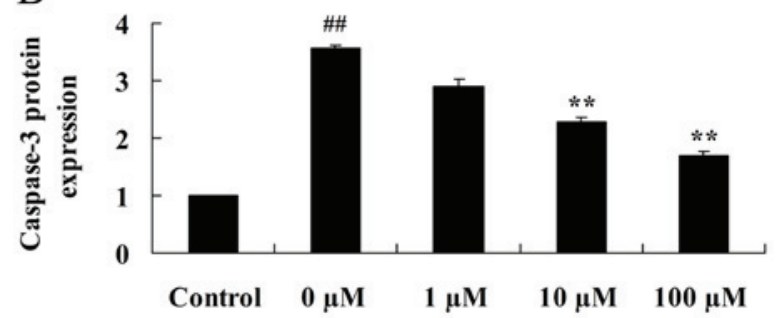

Figure 6. Vitexin protects against isoflurane-induced caspase-3 activation. (A) Gel images and (B) quantitative analysis of caspase-3 protein expression in PC12 cells treated without (control) or with $2 \%$ isoflurane plus $0,1,10$ and $100 \mu \mathrm{M}$ vitexin by western blot analysis. ${ }^{\# \#} \mathrm{P}<0.01$ vs. control group; ${ }^{* *} \mathrm{P}<0.01$ vs. the $0 \mu \mathrm{M}$ vitexin-treated group.

A

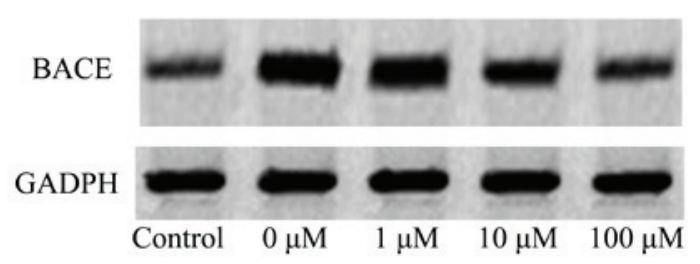

B

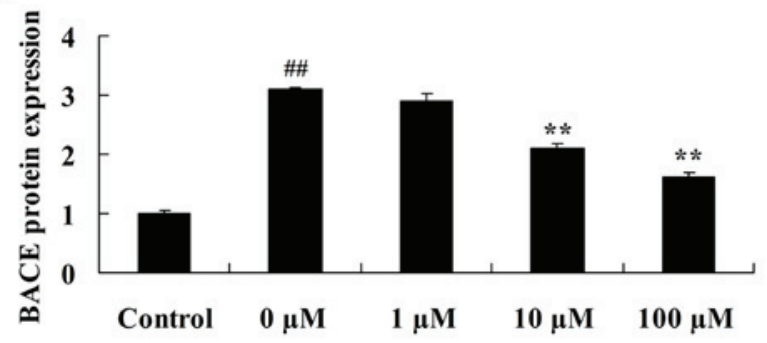

Figure 7. Vitexin protects against the isoflurane-induced increase in BACE levels. (A) Gel images and (B) quantitative analysis of BACE protein expression in $\mathrm{PC} 12$ cells treated without (control) or with $2 \%$ isoflurane plus $0,1,10$ and $100 \mu \mathrm{M}$ vitexin using western blot analysis. ${ }^{\# \prime} \mathrm{P}<0.01 \mathrm{vs}$. control group; ${ }^{* *} \mathrm{P}<0.01$ vs. the $0 \mu \mathrm{M}$ vitexin-treated group. BACE, $\beta$-secretase 1 .

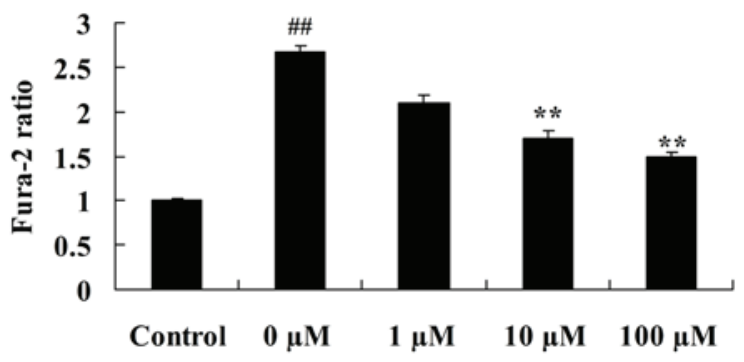

Figure 8. Vitexin protects against the isoflurane-induced increase in cytosolic calcium levels. The fura- 2 ratio in PC12 cells treated without (control) or with $2 \%$ isoflurane plus $0,1,10$ and $100 \mu \mathrm{M}$ vitexin. ${ }^{\# \#} \mathrm{P}<0.01$ vs. control group; ${ }^{* *} \mathrm{P}<0.01$ vs. the $0 \mu \mathrm{M}$ vitexin-treated group.

Vitexin protects against the isoflurane-induced increase in $N R 2 B$ expression levels. The NR2B subunit is a fundamental regulatory subunit of the NMDA receptor and serves an important role in its structure and function (29). Therefore, the final aim of the study was to determine whether NR2B protein expression is involved in mediating the neuroprotective effects of vitexin in isoflurane-treated PC12 cells. As shown in Fig. 10, treatment of isoflurane-induced PC12 cells with 10 and $100 \mu \mathrm{M}$ vitexin significantly suppressed isoflurane-induced NR2B protein expression levels ( $\mathrm{P}=0.0045$ and 0.0012 , respectively).

\section{Discussion}

Consistent with other inhaled anesthetics of the halogen family, isoflurane-mediated hyperpolarization of neurocytes decreases the excitability of the neural network (30). Inhalation aesthetics at low concentrations can noticeably inhibit the function of nicotinic receptors (31). In the present study, vitexin visibly increased the number of neuron cells in isoflurane-treated rats. In addition, vitexin increased the growth and reduced isoflurane-induced TNF- $\alpha$, IL-6, GSH and SOD levels in isoflurane-treated PC12 cells. Using a rat pup model, Min et al (22) demonstrated that vitexin reduces hypoxia-ischemia neonatal brain injury. Consistent with these observations, Dong et al (32) demonstrated that vitexin protects against myocardial ischemia/reperfusion injury through attenuating the inflammatory response. Furthermore, Borghi et al (33) observed that vitexin inhibits inflammation-associated pain through TRPV1 and oxidative stress.

Inhalation anesthetics used at concentrations higher than the clinical range may induce the following effects: Inhibition of the voltage susceptibility of $\mathrm{Na}^{+}, \mathrm{K}^{+}$and $\mathrm{Ca}^{2+}$, thereby reducing the transmission of harmful ostensive stimuli; promote the hyperpolarization of the cell membranes; relieve the overload of $\mathrm{Ca}^{2+}$; analgesia; anesthesia; and protective cerebral functions (34). Whether neurocytes can be protected against neurotoxicity, and the potential molecular and physiological mechanisms involved, has drawn substantial attention (35). A previous study demonstrated that isoflurane can induce cytotoxicity in different neurocytes at different concentrations and exposure times (36). The results of the present study demonstrated that vitexin significantly downregulated caspase-3 and BACE protein expression levels, and reduced ROS and cytosolic calcium levels in isoflurane-induced PC12 cells. Yang et al (23) provided evidence to suggest that vitexin protected the PC12 cells against $20 \mathrm{~h}$ of reoxygenation-induced 
A

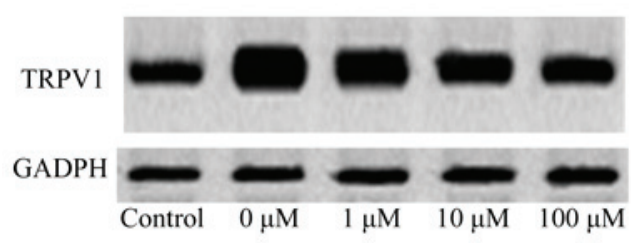

B

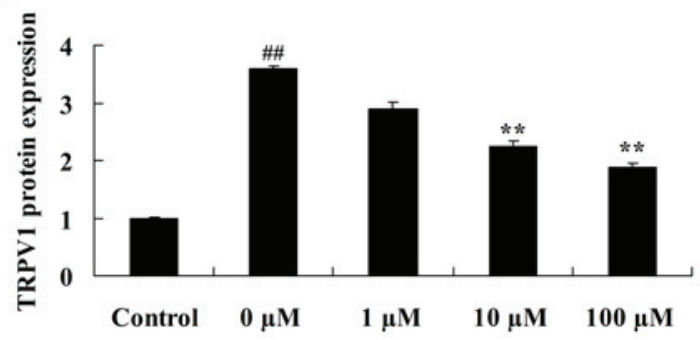

Figure 9. Vitexin protects against the isoflurane-induced increase in TRPV1 expression. (A) Gel images and (B) quantitative analysis of TRPV1 protein expression in PC12 cells treated without (control) or with $2 \%$ isoflurane plus $0,1,10$ and100 $\mu \mathrm{M}$ vitexin using western blot analysis. ${ }^{\#} \mathrm{P}<0.01$ vs. control group; ${ }^{* * *} \mathrm{P}<0.01$ vs. the $0 \mu \mathrm{M}$ vitexin-treated group. TRPV1, transient receptor potential cation channel subfamily $\mathrm{V}$ member 1 .

A

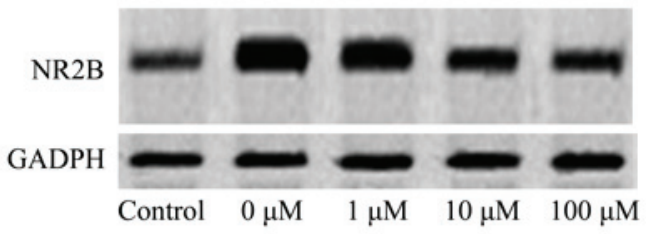

B

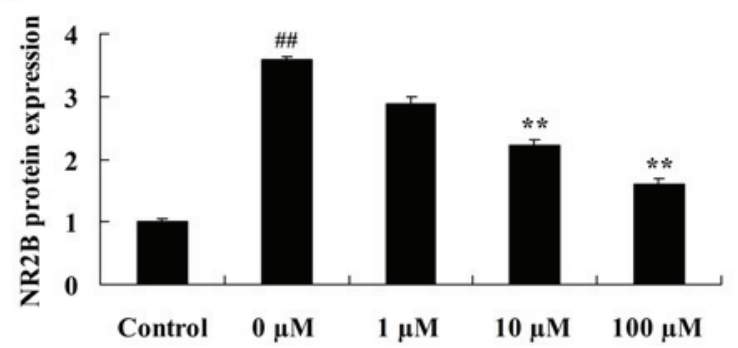

Figure 10. Vitexin protects against isoflurane-induced NR2B expression. (A) Gel images and (B) quantitative analysis of NR2B protein expression in PC12 cells treated without (control) or with $2 \%$ isoflurane plus $0,1,10$ and $100 \mu \mathrm{M}$ vitexin using western blot analysis. ${ }^{\# \#} \mathrm{P}<0.01$ vs. control group; ${ }^{* *} \mathrm{P}<0.01$ vs. the $0 \mu \mathrm{M}$ vitexin-treated group. NR2B, glutamate ionotropic receptor NMDA type subunit $2 \mathrm{~B}$.

injury, through a reduction in ROS production and caspase $3 / 7$ activities.

$\mathrm{Ca}^{2+}$ influx, mediated by the voltage-gated calcium channel, is an important mechanism for activating the presynaptic membrane (37). The TRPV4 receptor is a type of $\mathrm{Ca}^{2+}$ channel (24). A previous study reported that isoflurane-induced neurotoxicity in rats was associated with increased TRPV4 protein expression, which may have led to the over-activation of the TRPV4 receptor (38). Furthermore, a TRPV4-mediated $\mathrm{Ca}^{2+}$ influx was observed. Treatment with a TRPV4 receptor agonist was associated with increased $\mathrm{Ca}^{2+}$ and enhanced excitability of cells. An increase in the cellular excitability and the extension of depolarization may be responsible for increasing $\mathrm{Ca}^{2+}$ influx further (39). Through the influx of $\mathrm{Ca}^{2+}$, the TRPV4 receptor activity may promote the release of presynaptic glutamic acid. Moreover, additional receptors, such as the metabotropic glutamate receptor and nicotine acetylcholine receptor, also participate in regulating the release of glutamic acid from the presynaptic membrane (40). In the present study, vitexin significantly suppressed the expression levels of TRPV1 protein in isoflurane-induced PC12 cells. In addition, Borghi et al (33) demonstrated that vitexin inhibits inflammatory pain by targeting TRPV1 and oxidative stress in mice.

In the nervous tissues of mammals, the functional $\mathrm{N}$-methyl-D-aspartate (NMDA) receptor consists of NR1 and NR2 subunits (41). The NR2B subunit is a fundamental regulatory subunit of the NMDA receptor and serves an important role in its structure and function (29). Phosphorylation of NR2B may increase the opening rate and time of the NMDA receptor, resulting in increased ion influx (42). Selective NR2B subunit inhibitors prevent hypotonic-stimulated enhancement of NMDA receptor activity whereas, selective NR2A subunit inhibitors do not demonstrate any obvious alterations of the NMDA receptor following hypotonic stimulation (43). This suggests that the NR2B subunit may be an important target for the regulation of the NMDA receptor through the TRPV4 receptor (44). In the present study, vitexin significantly suppressed isoflurane-induced NR2B protein expression levels in PC12 cells. Consistent with these observations, Yang et al (45) reported that vitexin inhibited NMDA receptor activity in cultured cortical neurons.

In conclusion, the present study demonstrated that vitexin mediates neuroprotective effects against isoflurane-induced neurotoxicity by targeting the TRPV1 and NR2B signaling pathways. This suggests that vitexin may be a strong candidate as a neurotoxicity drug. However, these results require validation in further studies.

\section{References}

1. Qu X, Xu C, Wang H, Xu J, Liu W, Wang Y, Jia X, Xie Z, Xu Z, Ji C, et al: Hippocampal glutamate level and glutamate aspartate transporter (GLAST) are up-regulated in senior rat associated with isoflurane-induced spatial learning/memory impairment. Neurochem Res 38: 59-73, 2013.

2. Tanaka K, Kehl F, Gu W, Krolikowski JG, Pagel PS, Warltier DC and Kersten JR: Isoflurane-induced preconditioning is attenuated by diabetes. Am J Physiol Heart Circ Physiol 282: H2018-H2023, 2002.

3. Benveniste $\mathrm{H}$ and Makaryus R: Are we moving closer to noninvasive imaging and monitoring of neonatal anesthesia-induced neurotoxicity? Anesthesiology 125: 22-24, 2016.

4. Stary CM, Sun X and Giffard RG: Astrocytes protect against isoflurane neurotoxicity by buffering pro-brain-derived neurotrophic factor. Anesthesiology 123: 810-819, 2015. 
5. An J, Stadnicka A, Kwok WM and Bosnjak ZJ: Contribution of reactive oxygen species to isoflurane-induced sensitization of cardiac sarcolemmal adenosine triphosphate-sensitive potassium channel to pinacidil. Anesthesiology 100: 575-580, 2004.

6. Mazoit JX, Roulleau P and Baujard C: Isoflurane-induced neuroapoptosis in the neonatal rhesus macaque brain: Isoflurane or ischemia-reperfusion? Anesthesiology 113: 1245-1246, 2010.

7. Jiang $\mathbf{J}$ and Jiang $\mathrm{H}$ : Effect of the inhaled anesthetics isoflurane, sevoflurane and desflurane on the neuropathogenesis of Alzheimer's disease (review). Mol Med Rep 12: 3-12, 2015.

8. Wei H: The role of calcium dysregulation in anesthetic-mediated neurotoxicity. Anesth Analg 113: 972-974, 2011.

9. Pan C, Xu Z, Dong Y, Zhang Y, Zhang J, McAuliffe S, Yue Y, $\mathrm{Li} \mathrm{T}$ and Xie Z: The potential dual effects of anesthetic isoflurane on hypoxia-induced caspase- 3 activation and increases in $\beta$-site amyloid precursor protein-cleaving enzyme levels. Anesth Analg 113: 145-152, 2011

10. Jevtovic-Todorovic V, Kirby CO and Olney JW: Isoflurane and propofol block neurotoxicity caused by MK-801 in the rat posterior cingulate/retrosplenial cortex. J Cereb Blood Flow Metab 17: 168-174, 1997.

11. Bickler PE, Warren DE, Clark JP, Gabatto P, Gregersen M and Brosnan $\mathrm{H}$ : Anesthetic protection of neurons injured by hypothermia and rewarming: Roles of intracellular $\mathrm{Ca}^{2+}$ and excitotoxicity. Anesthesiology 117: 280-292, 2012.

12. Hara M, Zhou ZY, Hemmings HC Jr: $\alpha 2$-adrenergic receptor and isoflurane modulation of presynaptic $\mathrm{Ca}^{2+}$ influx and exocytosis in hippocampal neurons. Anesthesiology 125: 535-546, 2016.

13. Bickler PE, Zhan X and Fahlman CS: Isoflurane preconditions hippocampal neurons against oxygen-glucose deprivation: Role of intracellular $\mathrm{Ca}^{2+}$ and mitogen-activated protein kinase signaling. Anesthesiology 103: 532-539, 2005.

14. Gemes G, Oyster KD, Pan B, Wu HE, Bangaru ML, Tang Q and Hogan QH: Painful nerve injury increases plasma membrane $\mathrm{Ca}^{2+}$-ATPase activity in axotomized sensory neurons. Mol Pain 8: 46, 2012

15. Sanchez JC, Lopez-Zapata DF and Wilkins RJ: TRPV4 channels activity in bovine articular chondrocytes: Regulation by obesity-associated mediators. Cell Calcium 56: 493-503, 2014.

16. Jang Y, Jung J, Kim H, Oh J, Jeon JH, Jung S, Kim KT, Cho H, Yang DJ, Kim SM, et al: Axonal neuropathy-associated TRPV4 regulates neurotrophic factor-derived axonal growth. J Biol Chem 287: 6014-6024, 2012.

17. Ciurtin C, Majeed Y, Naylor J, Sukumar P, English AA, Emery P and Beech DJ: TRPM3 channel stimulated by pregnenolone sulphate in synovial fibroblasts and negatively coupled to hyaluronan. BMC Musculoskelet Disord 11: 111, 2010.

18. Heckel E, Boselli F, Roth S, Krudewig A, Belting HG, Charvin G and Vermot J: Oscillatory flow modulates mechanosensitive klf2a expression through trpv4 and trpp2 during heart valve development. Curr Biol 25: 1354-1361, 2015.

19. Nemethova M, Talian I, Danielisova V, Tkacikova S, Bonova P, Bober P, Matiasova M, Sabo J and Burda J: Delayed bradykinin postconditioning modulates intrinsic neuroprotective enzyme expression in the rat CA1 region after cerebral ischemia: A proteomic study. Metab Brain Dis: Jul 8, 2016 (Epub ahead of print).

20. Liu W, Guo Q, Hu X, Peng L and Zhou B: Induction of DJ-1 protects neuronal cells from isoflurane induced neurotoxicity. Metab Brain Dis 30: 703-709, 2015

21. Huang HC, Chang P, Lu SY, Zheng BW and Jiang ZF: Protection of curcumin against amyloid- $\beta$-induced cell damage and death involves the prevention from NMDA receptor-mediated intracellular Ca elevation. J Recept Signal Transduct Res 35: 450-457, 2015.

22. Min JW, Hu JJ,He M, Sanchez RM, Huang WX, Liu YQ, Bsoul NB, Han S, Yin J, Liu WH, et al: Vitexin reduces hypoxia-ischemia neonatal brain injury by the inhibition of HIF-1alpha in a rat pup model. Neuropharmacology 99: 38-50, 2015.

23. Yang ZB, Tan B, Li TB, Lou Z, Jiang JL, Zhou YJ, Yang J, Luo XJ and Peng J: Protective effect of vitexin compound B-1 agains hypoxia/reoxygenation-induced injury in differentiated PC12 cells via NADPH oxidase inhibition. Naunyn Schmiedebergs Arch Pharmacol 387: 861-871, 2014

24. Edwards JE, Brown PN, Talent N, Dickinson TA and Shipley PR: A review of the chemistry of the genus Crataegus. Phytochemistry 79: 5-26, 2012.

25. Wang Y, Zhen Y, Wu X, Jiang Q, Li X, Chen Z, Zhang G and Dong L: Vitexin protects brain against ischemia/reperfusion injury via modulating mitogen-activated protein kinase and apoptosis signaling in mice. Phytomedicine 22: 379-384, 2015.
26. Zhang B, Dong Y, Zhang G, Moir RD, Xia W, Yue Y, Tian M, Culley DJ, Crosby G, Tanzi RE and Xie Z: The inhalation anesthetic desflurane induces caspase activation and increases amyloid beta-protein levels under hypoxic conditions. J Biol Chem 283: 11866-11875, 2008.

27. Luo X, Yang L, Chen X and Li S: Tau hyperphosphorylation: A downstream effector of isoflurane-induced neuroinflammation in aged rodents. Med Hypotheses 82: 94-96, 2014.

28. Beckmann N, Doelemeyer A, Zurbruegg S, Bigot K, Theil D, Frieauff W, Kolly C, Moulin P, Neddermann D, Kreutzer R, et al: Longitudinal noninvasive magnetic resonance imaging of brain microhemorrhages in BACE inhibitor-treated APP transgenic mice. Neurobiol Aging 45: 50-60, 2016.

29. Li C, Zhang N, Hu Y and Wang H: NR2B overexpression leads to the enhancement of specific protein phosphorylation in the brain. Brain Res 1588: 127-134, 2014.

30. Su JY and Vo AC: Role of PKC in isoflurane-induced biphasic contraction in skinned pulmonary arterial strips. Anesthesiology 96: 155-161, 2002

31. Vahle-Hinz C, Detsch O, Siemers M and Kochs E: Contributions of GABAergic and glutamatergic mechanisms to isoflurane-induced suppression of thalamic somatosensory information transfer. Exp Brain Res 176: 159-172, 2007

32. Dong L, Fan Y, Shao X and Chen Z: Vitexin protects against myocardial ischemia/reperfusion injury in Langendorff-perfused rat hearts by attenuating inflammatory response and apoptosis. Food Chem Toxicol 49: 3211-3216, 2011.

33. Borghi SM, Carvalho TT, Staurengo-Ferrari L, Hohmann MS, Pinge-Filho P, Casagrande R and Verri WA Jr: Vitexin inhibits inflammatory pain in mice by targeting TRPV1, oxidative stress and cytokines. J Nat Prod 76: 1141-1149, 2013.

34. Ding W, Li Z, Shen X, Martin J, King SB, Sivakumaran V, Paolocci $\mathrm{N}$ and Gao WD: Reversal of isoflurane-induced depression of myocardial contraction by nitroxyl via myofilament sensitization to $\mathrm{Ca}^{2+}$. J Pharmacol Exp Ther 339: 825-831, 2011

35. Wang Q, Li K and Yao S: Effect of inhalational anesthetics on cytotoxicity and intracellular calcium differently in rat pheochromocytoma cells (PC12). J Huazhong Univ Sci Technolog Med Sci 28: 104-109, 2008

36. Xie Z, Dong Y, Maeda U, Moir R, Inouye SK, Culley DJ, Crosby $G$ and Tanzi RE: Isoflurane-induced apoptosis: A potential pathogenic link between delirium and dementia. J Gerontol A Biol Sci Med Sci 61: 1300-1306, 2006.

37. Harraz OF and Altier C: STIM1-mediated bidirectional regulation of $\mathrm{Ca}(2+)$ entry through voltage-gated calcium channels (VGCC) and calcium-release activated channels (CRAC). Front Cell Neurosci 8: 43, 2014

38. Shan H, Messi ML, Zheng Z, Wang ZM and Delbono O: Preservation of motor neuron $\mathrm{Ca}^{2+}$ channel sensitivity to insulin-like growth factor-1 in brain motor cortex from senescent rat. J Physiol 553: 49-63, 2003.

39. Sturek $\mathrm{M}: \mathrm{Ca}^{2+}$ regulatory mechanisms of exercise protection against coronary artery disease in metabolic syndrome and diabetes. J Appl Physiol (1985) 111: 573-586, 2011.

40. Feng Y, Wang B, Du F, Li H, Wang S, Hu C, Zhu C and Yu X: The involvement of PI3K-mediated and L-VGCC-gated transient $\mathrm{Ca}^{2+}$ influx in $17 \beta$-estradiol-mediated protection of retinal cells from $\mathrm{H} 2 \mathrm{O} 2$-induced apoptosis with $\mathrm{Ca}^{2+}$ overload. PLoS One 8: e77218, 2013.

41. Hogan-Cann AD and Anderson CM: Physiological roles of non-neuronal NMDA receptors. Trends Pharmacol Sci 37: 750-767, 2016

42. Zhang XN, Li JM, Yang Q, Feng B, Liu SB, Xu ZH, Guo YY and Zhao MG: Anti-apoptotic effects of hyperoside via inhibition of NR2B-containing NMDA receptors. Pharmacol Rep 62: 949-955, 2010

43. Li XB, Guo HL, Shi TY, Yang L, Wang M, Zhang K, Guo YY, Wu YM, Liu SB and Zhao MG: Neuroprotective effects of a novel translocator protein $(18 \mathrm{kDa})$ ligand, ZBD-2, against focal cerebral ischemia and NMDA-induced neurotoxicity. Clin Exp Pharmacol Physiol 42: 1068-1074, 2015.

44. Cho SI, Park UJ, Chung JM and Gwag BJ: Neu2000, an NR2B-selective, moderate NMDA receptor antagonist and potent spin trapping molecule for stroke. Drug News Perspect 23: 549-556, 2010.

45. Yang L, Yang ZM, Zhang N, Tian Z, Liu SB and Zhao MG: Neuroprotective effects of vitexin by inhibition of NMDA receptors in primary cultures of mouse cerebral cortical neurons. Mol Cell Biochem 386: 251-258, 2014. 